\title{
Comparing the Effect of Botulinum Toxin Type B Injection at Different Dosages for Patient with Drooling due to Brain Lesion
}

\author{
Hee Dong Park, M.D., Hyo Jae Kim, M.D., Sang Jun Park, M.D., Yong Min Choi, M.D. \\ Department of Physical Medicine and Rehabilitation, Seoul Medical Center, Seoul 131-130, Korea
}

\begin{abstract}
Objective To investigate Botulinum toxin type B (BNT-B) injection's effect and duration depending on dose for patients with brain lesion.

Method Twenty one patients with brain lesion and severe drooling were included and divided into three groups. All patients received conventional dysphagia therapy. Group A patients $(n=7)$ received an injection of 1,500 units and group B patients $(n=7)$ received an injection of 2,500 units of BNT-B in submandibular gland under ultrasound guidance. Group $C$ patients $(n=7)$ received conventional dysphagia therapy. Saliva secretion was assessed quantitatively at baseline and at weeks $1,2,4,8$, and 12 . The severity and frequency of drooling was assessed using the Drooling Quotient (DQ) by patients and/or caregivers.

Results Group A and B reported a distinct improvement of the symptoms within 2 weeks after BNT-B injection. Compared to the baseline, the mean amount of saliva decreased significantly throughout the study. However, there was no meaningful difference between the two groups. The greatest reductions were achieved at 2 weeks and lasted up to 8 weeks after BNT-B injection. Group C did not show any differences.

Conclusion Local injection of 1,500 units of BNT-B into salivary glands under ultrasonic guidance proved to be a safe and effective dose for drooling in patient with brain lesion, as did 2,500 units.
\end{abstract}

Key Words Botulinum toxin, Drooling, Brain lesion, Ultrasound, Submandibular gland

Received May 10, 2012; Accepted August 19, 2012

Corresponding author: Hyo Jae Kim

Department of Physical Medicine and Rehabilitation, Seoul Medical Center, 156, Sinnae-ro, Jungnang-gu, Seoul 131-130, Korea

Tel: +82-2-2276-7474, Fax: +82-2-2276-8504, E-mail: amaranth@hanmail. net

(C) This is an open-access article distributed under the terms of the Creative Commons Attribution Non-Commercial License (http:// creativecommons.org/licenses/by-nc/3.0) which permits unrestricted noncommercial use, distribution, and reproduction in any medium, provided the original work is properly cited.

Copyright $\odot 2012$ by Korean Academy of Rehabilitation Medicine

\section{INTRODUCTION}

Drooling is caused by drugs, infection or anatomical abnormality of oral cavity. Drooling is also observed in patients with aphasia caused by diseases of central nervous system such as cerebral palsy, stroke and Parkinson's disease. ${ }^{1}$ It is reported that $75 \%$ of Parkinson's disease patients and $10-37 \%$ of cerebral palsy patients are affected with drooling. ${ }^{2,3}$

Anticholinergic agents such as trixexyphenidyl, benzotropine, atropine and scopolamine are used to treat drooling, but their dose and duration are limited due to 
their adverse effects such as hyposecretion in internal organs other than salivary glands, micturition disorders caused by excessive bladder relaxation and especially in elderly patients, hallucination or confusion..$^{4-6}$ Partial sialoadenectomy or ligation/transposition of salivary glands can be a surgical treatment option, but both anesthesia and risk of facial nerve injury can be burdensome $^{7}$ and cysts may appear after salivary duct ligation. Transposition of salivary ducts can change the direction of drooling from antegrade to retrograde but cannot decrease the amount of salivation itself. Irradiation focused onto salivary glands is known to be effective for elderly patients who are contraindicated for medical or surgical treatments but may be complicated with anorexia and xerostomia. In addition, especially for pediatric patients, its use is limited because of risk of malignant neoplasm development after irradiation. ${ }^{1}$

Botulinum toxin, an agent which blocks neuromuscular junction, has been used to treat various motor disorders, and xerostomia after injection of the botulinum toxin has been reported with some frequency. ${ }^{8}$ Botulinum toxin also has been reported to be effective in reducing drooling in patients with amyotrophic lateral sclerosis who suffer from severe drooling. ${ }^{9}$ Because local injection of botulinum toxin is a simple procedure and has minimal systemic adverse effects, it has been reported to be effective in patients who are not candidates for surgical treatment. However, some side effects such as palsy of medial and lateral pterygoid muscles, xerostomia and weakness of masticatory muscles caused by excessive diffusion of botulinum toxin have been reported. But there are few studies on proper injection method and dose of botulinum toxin for reducing drooling in patients with brain lesion.

Hence the purpose of this study is to evaluate the efficacy and duration of effect of botulinum toxin in patients who suffer from excessive drooling caused by brain lesion, checking two dose levels injected into salivary glands. Botulinum toxin was injected under the guidance of ultrasonography for confirmation of precise injection sites.

\section{MATERIALS AND METHODS}

\section{Subjects}

This is a prospective study and the subjects were inpatients between November 2009 and March 2012, who expressed discomfort over excessive drooling caused by brain lesion such as stroke of post-acute phase or traumatic brain injury, or whose caretakers have had difficulty caring for the patients' drooling. At the time of study entry, patients were permitted to continue their own medications for brain lesion but anticholinergic agents were discontinued 30 days before entry. In addition, patients who received botulinum toxin injection for treatment of joint stiffness within 3 months were excluded.

To estimate sample size, IBM SPSS samplePower3 IBM (Armonk, New York, USA) was used and as a result, given mean value and standard deviation from data of previous similar studies, ${ }^{10}$ proper size of each group was calculated to be 7 with Power $90 \%$. Among 21 patients recruited, 16 patients were male and 5 patients were female, and their mean age was $52.7 \pm 15$.4. Mean period from brain injury to botulinum toxin injection was $31.0 \pm 19.8$ months. All subjects were receiving dysphagia treatment at the time of study entry.

Two thousand five hundred units of botulinum toxin, which Ondo et al. ${ }^{11}$ reported to be effective, and 1,500 units of botulinum toxin were used. Twenty one tags were numbered from 1 to 21 and divided into 3 groups randomly, and then patients were assigned to the group which included their numbers. Patients of treatment groups were treated with 1,500 units (Group A) and 2,500 units (Group B) of botulinum toxin, and patients of the other group (Group C) were not treated with botulinum toxin and only dysphagia treatment was done. No patients withdrew during the study.

\section{Injection technique}

In the resting state without drinking or eating $60-70 \%$ of saliva is secreted from submandibular gland, and with gustatory stimulation, additional saliva is secreted from parotid gland to help mastication and digestion. ${ }^{12}$ Botulinum toxin was injected selectively into the parotid gland because the purpose of this study is reducing salivary secretion not during eating but during resting or daily activity.

Patients were asked to lie in supine position and a cushion was placed under their neck to hyperextend the neck and expose the parotid gland. Using 12-5 MHz linear transducer of ultrasonographic device Phillips HD 15, a $22 \mathrm{G}$ (length: $6 \mathrm{~cm}$ ) needle was inserted under the ultrasonic guidance. The tip of the needle was confirmed to be located not in nerve, blood vessel or salivary duct but 


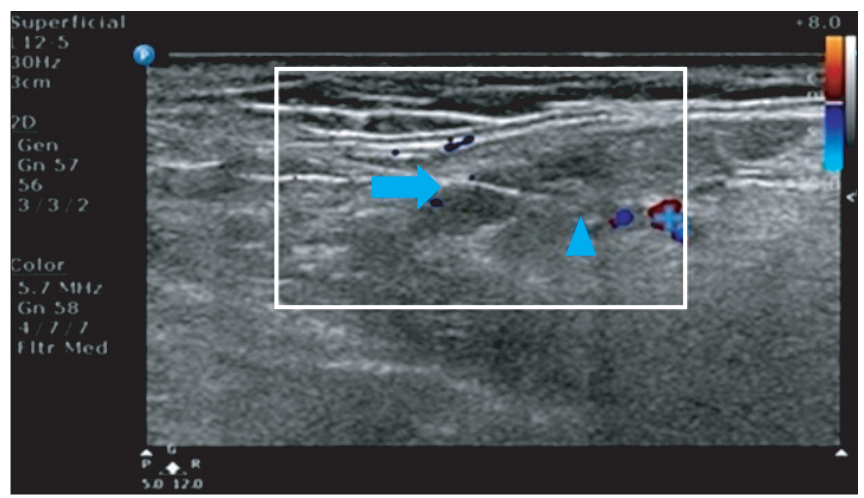

Fig. 1. Ultrasound-guided injection into the submandibular gland. The needle is positioned along the longitudinal axis of the transducer (arrow sign: needle tip, triangle sign: submandibular gland, cross sign: facial artery).

in parenchyma of salivary gland, and botulinum toxin B Myobloc (Elan Pharmaceuticals, San Francisco, USA) was then injected. In total 1,500 and 2,500 units of botulinum toxin was injected into bilateral parotid gland with 750 units (Group A) and 1,250 units (Group B) for each side of gland, and injection was performed in 2 separated sites (Fig. 1). 1,500 and 2,500 units of botulinum toxin was diluted in $1 \mathrm{cc}$ of normal saline to be fully diffused throughout the parenchyma of the salivary gland. Except for pain caused by the injection, no adverse effects such as fever, convulsion and anaphylaxis were reported. Patients were asked to report to investigators when atrophy or weakness of oral muscles including masticator muscles or xerostomia is observed.

\section{Measurement of amount of drooling}

Amount of drooling was evaluated in botulinum toxin treatment groups before injection and at weeks 1, 2, 4, 8 and 12 after injection. Amount of drooling was measured by weighing the gauzes which were inserted at the entrance of bilateral submandibular glands for 20 minutes in sitting position. To minimize diurnal variation, measuring was performed between 5 p.m. and 6 p.m. after daily treatment and before dinner. Before measuring, drinking or eating was limited for at least one hour in order that the amount of salivary secretion in resting state could be measured as possible. Frequency and degree of drooling was evaluated using Teacher drooling scale (TDS) and Drooling severity scale (DSS) (Appendix 1). ${ }^{13,14}$

In Group C, amount of drooling was evaluated before dysphagia treatment and at weeks 1, 2, 4 after the treat- ment, and method and timing of measuring was same as above.

\section{Dysphagia treatment}

All the subjects kept taking conventional dysphagia rehabilitation treatment and electric stimulation treatment. For electric stimulation treatment, as Freed et al., ${ }^{15}$ electrodes were attached to the points of maximal muscle twitch near digastric muscles and thyrohyoid muscles. This treatment was performed for 30 minutes a day, 5 days a week, until the day of final drooling amount measurement. Stimulation was performed with intensity of $5 \mathrm{~mA}$ to maximum $15.0 \mathrm{~mA}$, up to which the patient can endure.

\section{Statistical analysis}

SPPS version 18.0 for Windows was used for statistical analysis (SPSS, Inc, an IBM Company, Chicago, Illinois, USA). Repetitive measured ANOVA was performed to analyze changes of the amount of salivation before injection and weeks 1, 2, 4, 8, 12 after injection in botulinum toxin injection groups, and before treatment and weeks 1, 2, 4 after treatment in dysphagia treatment only group. Differences of drooling amount at the same time period between two botulinum toxin injection groups were statistically analyzed using Mann-Whitney test. Null hypotheses of no difference were rejected if $p$-values were less than 0.05 .

\section{RESULTS}

A total of 21 brain lesion patients were enrolled in this study. Their underlying diseases were cerebral infarction in 6 patients, intracranial hemorrhage in 9 patients, and hypoxic brain damage in 6 patients. The ages ranged from 29 to 82 , and mean duration of disease was 31 months. Eight patients were able to take foods orally and the other 13 patients were fed via tube (Table 1). All patients were observed to have antegrade drooling in sitting position.

\section{Comparison of the amount of salivation}

The amount of salivation in Group A and B was shown by Table 2 and Fig. 2. In both groups mean amount of salivation decreased significantly until 8 weeks after injection compared to before injection $(\mathrm{p}<0.05)$. Maximal decrease of the amount of salivation was observed at 2 weeks after injection but degree of the decrease over time 
Table 1. Demographic Characteristics of the Subjects

\begin{tabular}{|c|c|c|c|}
\hline Characteristics & $\begin{array}{c}\text { Group A } \\
(1,500 \text { Unit })\end{array}$ & $\begin{array}{c}\text { Group B } \\
(2,500 \text { Unit })\end{array}$ & $\begin{array}{c}\text { Group C } \\
\text { (Conventional therapy) }\end{array}$ \\
\hline Number (N) & 7 & 7 & 7 \\
\hline Age & $51.1 \pm 11.5$ & $54.3 \pm 17.2$ & $52.7 \pm 18.9$ \\
\hline $\operatorname{Sex}(M / F)$ & $4 / 3$ & $6 / 1$ & $6 / 1$ \\
\hline $\begin{array}{l}\text { Diagnosis } \\
\text { Ischemic/hemorrhagic/hypoxic brain damage }\end{array}$ & $3 / 3 / 1$ & $2 / 3 / 2$ & $1 / 3 / 3$ \\
\hline Duration to onset (months) & $31.4 \pm 20.0$ & $34.9 \pm 26.1$ & $26.5 \pm 13.4$ \\
\hline $\begin{array}{l}\text { Feeding method } \\
\text { Oral/tube feeding }\end{array}$ & $4 / 3$ & $2 / 5$ & $2 / 5$ \\
\hline
\end{tabular}

Table 2. Salivary Flow Rate (g/20 min)

\begin{tabular}{lcccccc}
\hline & Baseline & 1 weeks & 2 weeks & 4 weeks & 8 weeks & 12 weeks \\
\hline Group A & $3.88 \pm 1.36$ & $2.91 \pm 1.74^{*}$ & $1.98 \pm 1.47^{*}$ & $1.55 \pm 0.63^{*}$ & $2.03 \pm 0.86^{*}$ & $2.24 \pm 1.10$ \\
p-value & & 0.011 & 0.001 & 0.038 & 0.006 & 0.066 \\
Group B & $4.08 \pm 2.11$ & $3.02 \pm 2.02^{*}$ & $1.94 \pm 1.70^{*}$ & $1.80 \pm 1.53^{*}$ & $2.06 \pm 1.30^{*}$ & $2.92 \pm 1.38$ \\
p-value & & 0.009 & 0.000 & 0.004 & 0.002 & 0.071 \\
Group C & $3.30 \pm 1.23$ & $3.04 \pm 0.82$ & $3.53 \pm 1.62$ & $3.10 \pm 0.95$ & \\
p-value & & 0.240 & 0.335 & 0.198 & \\
\hline
\end{tabular}

Shows significant change between baseline and after botulinum toxin injection until 8 weeks ${ }^{*} \mathrm{p}<0.05$ comparison between baseline and post-treatment by repetitive measured ANOVA

Table 3. Teacher Drooling Scale \& Drooling Severity Scale

\begin{tabular}{|c|c|c|c|c|c|c|}
\hline & \multicolumn{2}{|c|}{ Group A } & \multicolumn{2}{|c|}{ Group B } & \multicolumn{2}{|c|}{ Group C } \\
\hline & TDS & DSS & TDS & DSS & TDS & DSS \\
\hline Baseline & 4.43 & 4.29 & 4.29 & 4.29 & 3.42 & 3.14 \\
\hline 1 weeks & 3.00 & 3.00 & 2.86 & 3.00 & 3.14 & 3.29 \\
\hline 2 weeks & 2.57 & 1.71 & 2.29 & 1.85 & 3.57 & 3.29 \\
\hline 4 weeks & 2.57 & 2.00 & 2.42 & 2.14 & 3.29 & 3.42 \\
\hline 8 weeks & 3.29 & 2.43 & 2.71 & 2.29 & & \\
\hline 12 weeks & 4.28 & 3.14 & 3.14 & 3.14 & & \\
\hline
\end{tabular}

was not significantly different between two groups.

In Group C, the amount of salivation was shown by Table 2 and Fig. 2. There was no significant difference between before and after treatment.

\section{Teacher Drooling Scale (TDS) and Drooling Severity} Scale (DSS)

Average TDS and DSS score of all the subjects were 4 or more, and improvement of 2 or more points after treatment was defined to be successful. In botulinum toxin injection groups, significant differences were observed at week 1 after injection $(\mathrm{p}<0.05)$ and the effect continued till week 12 maximally (Table 3 ). However there were no significant differences between two groups. In Group C, no significant difference was observed between before and after treatment.

\section{DISCUSSION}

Saliva is secreted from the parotid gland, submandibular gland and sublingual gland, and acts as digestive juice, antimicrobial and sterilizing agent, lubricant, and maintains oral water content, oral hygiene, dental health and fresh breath. However, excessive drooling may ir- 


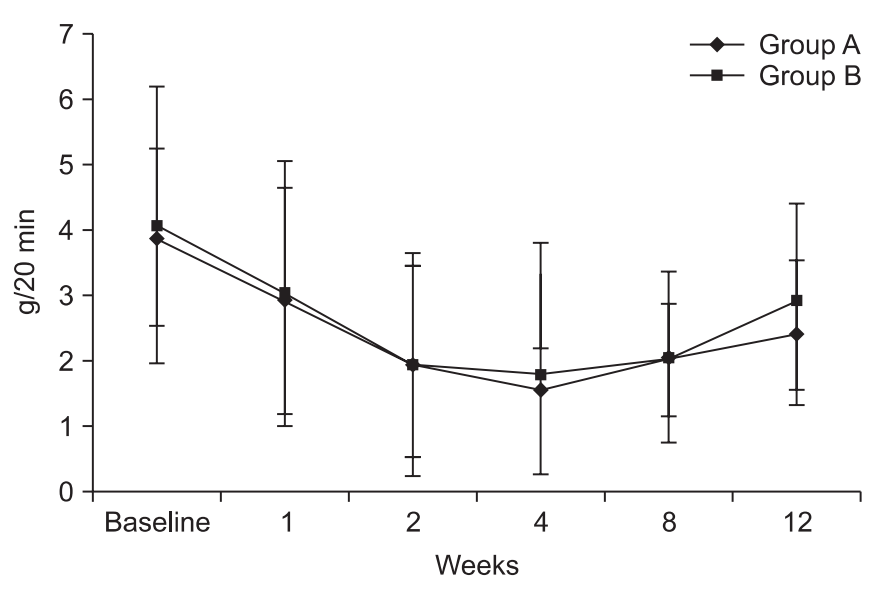

Fig. 2. Salivary flow rate: mean in time. Peak effect of BTX-B was at 2-4 weeks. Production of saliva went back to baseline approximately 12 weeks.

ritate perioral tissue and increase risk of infection, and in severe cases, foul odor and even dehydration can develop. ${ }^{7,16}$

Drooling is frequently observed together with hypersecretion of saliva, and actually it has been reported that hypersecretion of saliva is accompanied by ineffective swallowing of saliva in children affected with cerebral palsy. ${ }^{17}$ In a study on brain damaged patients, there was no difference in amount and acidity of saliva compared with healthy group and rather impairment of cognitive function was remarkable in patients with excessive drooling. ${ }^{18}$ Medication with anticholinergics, direct surgical manipulation on salivary glands, irradiation of salivary glands and injection of botulinum toxin are methods of reducing salivary secretion.

Botulinum toxin consists of 7 subtypes which have similar structures but are different from each other in immunologic profile, and of those subtypes, type A has been used clinically the most, for example, treating muscular rigidity and also drooling. In a study on patients who suffer from drooling, botulinum toxin type A was proved to be effective after 2 weeks of treatment. ${ }^{19}$ Duration of the effect was observed to be maximally 24 weeks in a study which used Dysport, botulinum toxin type A. ${ }^{18}$ Ondo et al. ${ }^{11}$ used botulinum toxin type B for Parkinson's disease patients and reported that the amount of saliva decreased after 4 weeks of injection. However, there are few studies comparing effects of each subtype. In this study, type B also was observed to have 12 weeks of duration. In addition, Food and Drug Administration (FDA) recommends that botulinum toxin type A should be used in 4 hours af- ter dilution, and because type B has no such limitation in storage and use, type B can be more effective in drooling treatment.

In this study we evaluated the efficacy of botulinum toxin injection by dose injected. Dressler et al. ${ }^{20}$ used 4,000 units of botulinum toxin type B and Ondo et al. ${ }^{11}$ used 2,500 units of botulinum toxin and reported significant decrease in the amount of salivation, but there is no study on proper dose of botulinum toxin.

Study on proper dose of botulinum toxin is considered to be important because botulinum toxin is an expensive agent and once minimal effective dose is confirmed, patients can benefit considerably by reducing their medical expenses. In this study, 2,500 units of botulinum toxin type B which has been proved to be efficient by Ondo et al. ${ }^{11}$ and 1,500 units, which is 1,000 units subtracted dose from it, were injected. Because the volume of botulinum toxin injected was $1 \mathrm{cc}$ or less, a minute error could cause a significant difference in the concentration of botulinum toxin. So for convenience and precision of preparation, we decided not to use 1,250 units of botulinum toxin which is half of 2,500 units, but to use 1,500 units.

No significant differences in the amount of salivation was observed between 1,500 unit group and 2,500 unit group for 12 weeks after injection. This can be considered to be the result of the effect of botulinum toxin itself. However, it is more convincing that injection in proper sites under ultrasonography guidance, sufficient dose diffusion caused the effect.

Cases of adverse effects such as palsy of perioral muscles, xerostomia and weakness of masticatory muscles were reported before but in this study, no adverse effect was reported except for pain caused by needle. Xerostomia was especially of concern but no subjects reported discomfort of daily life caused by xerostomia. On the contrary, botulinum toxin injection may be considered to be efficient in treating drooling by reducing caretaking burden.

This study has some limitation. First, the amount of salivation can vary under the influence of patient's condition and environmental changes and if this variation is considerable, overall test results and statistical significance can be biased. So in order to minimize such variation, the amount of salivation was measured by the same investigator and the measurement was always performed between 5 p.m. and 6 p.m. before dinner. Secondly, bias caused by different sites of brain injury, different under- 
lying pathologies and different duration of disease before injection was not completely ruled out. In the future, comprehensive studies on subjects with similar pathology and duration of disease should be performed.

\section{CONCLUSION}

Despite its disadvantage that repeated injection is needed to continue the effect, botulinum toxin injection can be considered to be an efficient treatment option for drooling because it is less invasive than surgery and has fewer systemic adverse effects than medication. In this study, 1,500 units of botulinum toxin, less than previously known effective dose, was proven to be enough for reducing drooling for the same duration. Hence in order to increase the efficacy and the duration of its effect, precise injection of botulinum toxin under the guidance of ultrasonography rather than increasing the dose of injection can result in higher benefit to the cost for patients.

\section{REFERENCES}

1. Hockstein NG, Samadi DS, Gendron K, Handler SD. Sialorrhea: a management challenge. Am Fam Physician 2004; 69: 2628-2634

2. Hussein I, Kershaw AE, Tahmassebi JF, Fayle SA. The management of drooling in children and patient with mental and physical disablities: a literature review. Int J Pediartr Dent 1998; 8: 3-11

3. Proulx M, de Courval FP, Wiseman MA, Panisset M. Salivary production in Parkinson's disease. Mov Disord 2005; 20: 204-207

4. Giess R, Naumann M, Werner E, Riemann R, Beck M, Puls I, Reiners C, Toyka KV. Injections of botulinum toxin A into the salivary glands improve sialorrhoea in amyotrophic lateral sclerosis. J Neurol Neurosurg Psychiatry 2000; 69: 121-123

5. Suskind DL, Tilton A. Clinical study of botulinum-A toxin in the treatment of sialorrhea in children with cerebral palsy. Laryngoscope 2002; 112: 73-81

6. Banerjee KJ, Glasson C, O'Flaherty SJ. Parotid and submandibular botulinum toxin A injections for sialorrhoea in children with cerebral palsy. Dev Med Child Neurol 2006; 48: 883-887

7. Mankarious LA, Bottrill ID, Huchzermyer PM, Bailey CM. Long-term follow-up of submandibular duct rerouting for the treatment of sialorrhea in the pediatric population. Otolaryngol Head Neck Surg 1999; 120: 303-307

8. Brin MF, Lew MF, Adler CH, Comella CL, Factor SA, Jankovic J, O'Brien C, Murray JJ, Wallace JD, WillmerHulme A, et al. Safery and efficacy of NeuroBlock (botulinum toxin type B) in type A-resistant cervical dystonia. Neurology 1999; 53: 1431-1438

9. Bushara KO. Sialorrhea in amyotrophic lateral sclerosis: a hypothesis of a new treatment - botulinum toxin A injections of the parotid glands. Med Hypotheses 1997; 48: 337-339

10. Lagalla G, Millevolte M, Capecci M, Provinciali L, Ceravolo MG. Long-lasting benefits of botulinum toxin type B in Parkinson's disease-related drooling. J Neurol 2009; 256: 563-567

11. Ondo WG, Hunder C, Moore W. A double-blind placebo-controlled trial of botulium toxin B for sialorrhea in Parkinson's diease. Neurology 2004; 62: 37-40

12. Enfors BO. The parotid and submandibular secretion in man. Quantitative recordings of the normal and pathological activity. Acta Otolaryngol Suppl 1962; 172: 1-67

13. Jongerius $\mathrm{PH}$, van Hulst $\mathrm{K}$, vanden Hoogen FJ, Rotteveel JJ. The treatment of posterior drooling by botulinum toxin in a child with cerebral palsy. J Pediatr Gastroenterol Nutr 2005; 41: 351-353

14. Banerjee KJ, Glasson C, O'Flaherty SJ. Parotid and submandibular botulinum toxin A injections for sialorrhoea in children with cerebral palsy. Dev Med Child Neurol 2006; 48: 883-887

15. Freed ML, Freed L, Chatburn RL, Christian M. Electrical stimulation for swallowing disorders caused by stroke. Respir Care 2001; 46: 466-474

16. Kim H, Lee Y, Weiner D, Kaye R, Cahill AM, Yudkoff M. Botulinum toxin type A injection to salivary glands: combination with single event multilevel chemoineirolysis in 2 children with severe spastic qudriplegic cerebral palsy. Arch Phys Med Rehabil 2006; 87: 141144

17. Blasco PA, Allaire JH. Drooling in the developmentally disabled: management practices and recommendations. Consortium on drooling. Dev Med Child Neurol 1992; 34: 849-862

18. Bae HS, Park CI, Rha DW, Nam HS, Vaq SG, Min KH, Park JB. Factors affecting drooling in adult patients with traumatic brain injury. J Korean Acad Rehab Med 2006; 30: 424-429 
19. Jongerius PH, Joosten F, Hoogen FJ, Gabreels, FJ, Rotteveel JJ. The treatment of drooling by ultrasoundquided intraglandular injections of botulinum toxin type A into the salivary glands. Laryngoscope 2003;
113: $107-111$

20. Dressler D, Adib Saberi F, Benecke R. Botulinum toxin type B for treatment of axillar hyperhidrosis. J neurol 2002; 249: 1729-1732 
Hee Dong Park, et al.

Appendix 1. Teacher Drooling Scale \& Drooling Severity Scale

\begin{tabular}{cll}
\hline Scale & \multicolumn{1}{c}{ TDS } & \multicolumn{1}{c}{ DSS } \\
\hline 1 & No drooling & Never drools, dry \\
2 & Infrequent drooling, small amount & Mild, only lips wet \\
3 & Occasional drooling, intermittent all day & Moderate, wet on lips and chin \\
4 & Frequent drooling, but not profuse & Severe, clothing becomes wet \\
5 & Constant drooling, always wet & Profuse, clothing, hands, try, and objects become wet \\
\hline
\end{tabular}

